\title{
IMPLICAÇÕES FÁTICO-JURÍDICAS DA MP 520: A precariedade dos vínculos empregatícios nos Hospitais Universitários e o comprometimento de suas funções ${ }^{1}$
}

\author{
Aimeé Mastella Sampaio da Silva ${ }^{2}$ \\ Maicon Scariotti Lucca ${ }^{3}$ \\ Pedro Augusto François Bellinaso ${ }^{4}$
}

\begin{abstract}
RESUMO: A Medida Provisória 520 visou criar uma Empresa Pública a fim de gerir a prestação de serviços médico-hospitalares, bem como a contratação de mão de obra em relação aos Hospitais Universitários. Esta medida objetivava sanar o problema referente à terceirização irregular nestes hospitais, mas gerou várias preocupações sobre o comprometimento destes em relação aos princípios das universidades. Veio permitir também, a manutenção dos contratos irregulares vigentes e a criação de novas terceirizações, em flagrante desrespeito à Constituição Federal e às decisões do Tribunal de Contas, o que gerou o ajuizamento de uma Ação Direta de Inconstitucionalidade. A situação dos Hospitais Universitários é insustentável. Esta percepção deve ser coadunada a partir da realização de um debate na sociedade sobre a melhor forma de gestão desse patrimônio público tão sensível e necessário.
\end{abstract}

PALAVRAS-CHAVE: Hospitais - Universidade - Terceirização.

\section{Fatic Legal Implications of MP 520: The precariousness of employment contracts in University Hospitals and the commitment of its functions.}

\begin{abstract}
The Provisional Measure 520 was aimed at creating a Public Company in order to manage the provision of medical and hospital services, as well as the hiring of labor to University Hospitals. This measure was intended to remedy the problem concerning the irregular outsourcing in these hospitals, however generated several concerns about the commitment to the universities principles. Also has allowed the irregular maintenance of existing contracts and the creation of new outsourcing, in flagrant disregard of the Constitution and decisions of the Court of Auditors, which led to the filing of a direct action of unconstitutionality. The situation in University Hospitals is unsustainable. This perception must be coalescing from a debate in society about how to manage these public assets so sensitive and necessary.
\end{abstract}

KEY-WORDS: Hospital - University - Outsourcing.

\section{INTRODUÇÃO}

Existem 45 hospitais universitários no Brasil, sendo que 44 são órgãos de universidades federais, não possuindo personalidade jurídica própria. Atuam em programas de ensino e pesquisa das universidades, além de prestarem um relevante

\footnotetext{
${ }^{1}$ Referência sobre o trabalho.

${ }^{2}$ Acadêmica de Direito, UFSM.

${ }^{3}$ Acadêmico de Direito, UFSM.

${ }^{4}$ Acadêmico de Direito, UFSM.
} 
serviço à sociedade, constatando a realização de 39,7 milhões de procedimentos em $2009^{5}$ exclusivamente pelo Sistema Único de Saúde (SUS).

A Medida Provisória 520, editada em 31 de dezembro de 2010, último dia do governo Lula, visou criar a Empresa Brasileira de Serviços Hospitalares (EBSERH). Esta empresa pública seria destinada a gerir a prestação de serviços médicohospitalares, bem como a contratação de mão de obra em relação a estes hospitais.

Tal medida não entrou em vigor, pois não foi apreciada pelo Senado Federal no tempo máximo previsto em lei. Devido à caducidade e às peculiaridades de seu rito, ela não poderá ser editada com o idêntico teor pela atual Presidenta. Todavia nada impede a propositura de projeto de lei por membro do legislativo federal.

\section{CONSIDERAÇÕES SOBRE OS HOSPITAIS UNIVERSITÁRIOS}

\subsection{Conceito de Hospitais Universitários}

Os Hospitais Universitários (HUs) e hospitais-escola da administração pública federal são predominantemente órgãos pertencentes às universidades federais. Estas, que consistem em entidades públicas integrantes da Administração Pública Indireta, são dotadas de personalidade jurídica própria e voltadas à finalidade educacional, em três bases: ensino, pesquisa e extensão (conhecidos como o Tripé Educacional). Diferem da generalidade dos entes que compõe a Administração Pública Indireta pelo atributo da autonomia institucional que lhe é inerente, em face do que dispõe o art. 207 da Constituição Federal (in verbis):

Art. 207. As universidades gozam de autonomia didático-científica, administrativa $e$ de gestão financeira e patrimonial, e obedecerão ao princípio de indissociabilidade entre ensino, pesquisa e extensão.

Os hospitais supracitados funcionam como órgãos suplementares, subordinados à Reitoria, com atuação nas funções de ensino, pesquisa e assistência à comunidade. Em geral, não têm existência independente, nem personalidade jurídica própria; operam como instrumentos a serviços das comunidades na realização de seu mister constitucional e dispõem de limitada autonomia administrativa para a gestão das suas

\footnotetext{
${ }^{5}$ Medida Provisória 520, exposição de motivos.
} 
atividades e serviços. Sua atuação é voltada basicamente para o apoio aos programas de ensino e pesquisa das universidades, mas também prestam serviços médico-hospitalares diretamente ao Sistema Único de Saúde - SUS.

No caput do art. 207, encontram-se os dois princípios estruturantes das universidades públicas brasileiras: o princípio da autonomia administrativa universitária, que protege as universidades contra interferências indevidas em seus assuntos didático-científico, administrativos e de gestão financeira patrimonial, além do princípio da indissociabilidade entre ensino, pesquisa e extensão (as três funções que estruturam o modelo de universidade hoje em rigor).

A autonomia administrativa universitária não é absoluta. Existem limites a serem observados, mas estes devem ter como base a Constituição Federal. Não pode o Executivo ou o Legislador Infraconstitucional ir além do que dispôs o constituinte, ou seja, somente é possível aplicar restrições à autonomia da universidade, analisando sistematicamente os dispositivos constitucionais.

Quanto à função de ensino, a estrutura dos hospitais universitários apresenta-se como pressuposto da própria atividade docente dos cursos de saúde das universidades. Há a inclusão necessariamente de disciplinas práticas vinculadas a estes órgãos. Dessa maneira, se tornam possíveis a formação e o aperfeiçoamento profissional através do contato direto entre alunos e pacientes.

Quanto à extensão, a prestação de serviços gratuitos de assistência médicohospitalar é de grande relevância à comunidade. Permitem envolver as universidades a demandas e necessidades reais da sociedade, impedindo que a academia distancie-se da realidade local.

Quanto à pesquisa, os hospitais universitários além de oferecerem espaço ao estudo prático e à verificação empírica, promovem a oportunidade aos jovens profissionais da área da saúde o desenvolvimento e a inovação científica.

As três funções da Universidade são imprescindíveis ao pleno alcance de seus objetivos. Em recente entrevista "A diretora do Hospital Universitário de Santa Maria (HUSM), Elaine Resener, considera a formação de profissionais a 'missão nobre' dos Hospitais Universitários”. (BONOTO, CASTILHO e DORNELLES, 2011).

$\mathrm{O}$ argumento de melhoria da eficiência e transparência administrava explícito na MP gerou preocupações sobre o comprometimento dos princípios indissociáveis de ensino, pesquisa e extensão já que tinham na mais alta conta critérios quantitativos, preterindo os qualitativos. Objetivava soluções rápidas, mas possivelmente efêmeras 
pela rasa análise dos casos. Fixar "metas de desempenho", sem definição de indicadores, numa instituição de ensino é incompatível com sua finalidade. O processo de desenvolvimento da pesquisa médica necessita tempo.

O principal objetivo dos hospitais universitários é a formação de profissionais que podem atuar no sistema público de saúde, não deixando de lado a assistência à população. Para isso, é fundamental que os cursos ligados à área de saúde estejam estreitamente ligados a esses hospitais. "O HUSM é vital para que os cursos da área de saúde desenvolvam todo o seu projeto pedagógico. A formação dos profissionais da área depende da existência do HUSM como campo de prática”, opina o diretor do Centro de Ciências da Saúde da UFSM (CCS), professor Paulo Afonso Burmann. Segundo ele, o perigo mais imediato que a MP 520 oferece é a desvinculação dos hospitais universitários das Instituições Federais de Ensino Superior. (BONOTO, CASTILHO e DORNELLES, 2011)

\subsection{A situação trabalhista nos Hospitais Universitários}

Uma das grandes questões apontadas na Justificativa da MP 520 era a solução do problema referente à terceirização irregular nos hospitais universitários. Conforme o art. 37, II da $\mathrm{CF}$, é obrigatória realização de concursos públicos para a admissão de trabalhadores na Administração Pública, tanto direta quanto indireta. A contratação de empregadores por outra forma fere de forma explícita a Constituição, se não vejamos:

Art. 37. A administração pública direta e indireta de qualquer dos Poderes da União, dos Estados, do Distrito Federal e dos Municípios obedecerá aos princípios de legalidade, impessoalidade, moralidade, publicidade e eficiência e, também, ao seguinte:

II - a investidura em cargo ou emprego público depende de aprovação prévia em concurso público de provas ou de provas e títulos, de acordo com a natureza e a complexidade do cargo ou emprego, na forma prevista em lei, ressalvadas as nomeações para cargo em comissão declarado em lei de livre nomeação e exoneração; (grifos nossos)

O propósito da criação da EBSRH pela MP 520 veio permitir a manutenção dos contratos irregulares hoje vigentes e criação de novas terceirizações por meio de 
“contratação temporária em processo seletivo simplificado, baseado em análise do curriculum vitae" (JUSTIFICATIVA MP 520, 2010), em flagrante desrespeito à Constituição Federal e à autoridade das decisões do Tribunal de Contas. O intuito deste tribunal, ao proferir suas deliberações, visava sanar o problema diminuindo gradualmente a terceirização irregular de postos de trabalho da Administração Pública Federal Direta, autárquica e fundacional. Se houvesse, de fato, a promulgação de lei desta medida, só agravaria esta situação e burlaria a obrigatoriedade do concurso público.

Para o diretor geral do Hospital Universitário de Brasília (HUB), Gustavo Romero, "a regra anterior definia que as instituições públicas federais precisavam de uma autorização para contratar pela CLT, ou firmar um contrato temporário, quando o caminho normal é que haja concurso público e que os profissionais sejam admitidos em regime estatutário. A solução que está se propondo é que os novos funcionários sejam contratados por CLT, então criou-se uma empresa que tem essa prerrogativa". Atualmente, o HUB conta com 624 contratados de forma precária. "Esses profissionais são essenciais para o HUB e sem eles o funcionamento da instituição seria praticamente inviável”, explicou Romero. Ele ainda avalia que a medida permitia resolver o impacto negativo que o hospital sofre por utilizar parte dos recursos do SUS (Sistema Único de Saúde) para o pagamento de servidores em caráter precário. Segundo cálculos do HUB, o hospital tem $R \$ 1,4$ milhão de sua verba comprometida com o custeio de profissionais contratados. (VIANA, 2011)

De fato, a situação que envolve a contratação irregular de trabalhadores nas Universidades Públicas e, de resto, em toda Administração Pública Federal, não é nova e tem se agravado consideravelmente na última década. Não é de se espantar que o crescente número de terceirizações irregulares e o descontrole dos órgãos oficiais forçaram o Tribunal de Contas da União a preconizar a realização de concursos públicos para a progressiva substituição da mão-de-obra precária e terceirizada por trabalhadores concursados.

Nesse contexto fático foi editada a Medida Provisória $\mathrm{n}^{\circ} 520$, em resposta às decisões proferidas pelo TCU, especialmente a do Acórdão $\mathrm{n}^{\circ}$ 1520/2006 que estabeleceu prazo de 2006 a 2010 para a diminuição gradual da terceirização irregular 
de postos de trabalho da Administração Pública Federal Direta, autárquica e fundacional.

\section{DEFINIÇÃO DE INSTITUIÇÃO DE APOIO}

A partir destas constatações, é necessário tecer alguns comentários sobre outras instituições, como as fundações de apoio, de forma a demonstrar e diferenciar das empresas públicas suas peculiaridades e características.

As fundações de apoio são instituições criadas com a finalidade de fomentar “projetos de ensino, pesquisa e extensão e de desenvolvimento institucional, científico e tecnológico, inclusive na gestão administrativa e financeira estritamente necessária à execução desses projetos ${ }^{\prime 6}$. Atuam em conjunto com Instituições Federais de Ensino Superior (IFES) e demais Instituições Científicas e Técnológicas ${ }^{7}$ (ICTs). Sua função é portanto, restrita aos projetos desenvolvidos em parceria com as IFES e as ICTs.

São constituídas na forma de fundações de direito privado sem fins lucrativos e regidas pelo Código Civil Brasileiro. Por sua característica de fundação de direito privado, tem a faculdade de contratar sua mão de obra no regime celetista por meio de processo seletivo público.

As fundações de apoio devem prezar pelos mesmos princípios da administração pública: legalidade, impessoalidade, moralidade, publicidade, economicidade e eficiência. Cabe ressaltar a necessidade de, ao utilizar recursos públicos, observar os trâmites licitatórios, bem como prestar contas aos órgãos de controle.

Os recursos para os projetos provêem indiretamente da União, via Agencias Financeiras Oficiais de Fomento, a Financiadora de Estudos e Projetos (FINEP) e o Conselho Nacional de Desenvolvimento Científico e Tecnológico (CNPq), por exemplo. Tais instituições podem celebrar contratos por prazo determinado com as fundações de apoio. As outras fontes de recursos das fundações são as doações de particulares e as receitas decorrentes de seu patrimônio.

Por derradeiro cabe constatar que o objetivo das fundações de apoio é dinamizar a aplicação de recursos em pesquisa, ensino e extensão, dando suporte e maior autonomia a outras instituições a elas ligadas, a fim de gerir suas bases de uma forma adequada e quiçá, aprimorada.

\footnotetext{
${ }^{6}$ Lei $8.958 / 95$, art. $1^{\circ}$.

${ }^{7}$ Lei $10.973 / 04$, art. $2^{\circ}$, V.
} 


\section{O PASSIVO TRABALHISTA CRIADO PELA DINÂMICA ATUAL}

Ponto relevante da medida provisória em tela é a discussão sobre a acumulação de um elevado passivo trabalhista pela administração pública. Dos 70.373 profissionais vinculados aos Hospitais Universitários 26.556 foram contratados por intermédio de fundações de apoio ${ }^{8}$. Tais funcionários foram contratados em regime celetista ou de prestação de serviços, configurando uma terceirização irregular pelo Poder Público.

A súmula 331 do Tribunal Superior do Trabalho trata da questão da terceirização irregular:

\section{CONTRATO DE PRESTAÇÃO DE SERVIÇOS.}

I - A contratação de trabalhadores por empresa interposta é ilegal, formando-se o vínculo diretamente com o tomador dos serviços, salvo no caso de trabalho temporário (Lei no 6.019, de 03.01.1974).

II - A contratação irregular de trabalhador, mediante empresa interposta, não gera vínculo de emprego com os órgãos da Administração Pública direta, indireta ou fundacional (art. 37, II, da CF/1988).

III - Não forma vínculo de emprego com o tomador a contratação de serviços de vigilância (Lei $n^{\circ}$ 7.102, de 20.06.1983) e de conservação e limpeza, bem como a de serviços especializados ligados à atividade-meio do tomador, desde que inexistente a pessoalidade e a subordinação direta.

A contratação de serviços terceirizados para executar atividade meio não gera vínculo empregatício. A contrario senso, portanto a contratação de terceirizados para atividade-fim da instituição gera vínculo empregatício. Todavia como os hospitais universitários fazem parte da administração indireta, tal situação é vedada pela Constituição Federal, que zela pela imprescindibilidade da realização de concurso público.

Esse aparente antagonismo pode induzir a uma aparente situação de impunidade aos tomadores. Todavia não é esta a posição da justiça trabalhista:

\footnotetext{
${ }^{8}$ Medida Provisória 520, exposição de motivos.
} 


\begin{abstract}
"Afigura-se necessário extremo cuidado com a invocação, pelas entidades de direito publico, do artigo 37, inciso II, da CF, para eximi-las da responsabilidade trabalhista em relação a pessoas que venham efetivamente a lhes prestar serviços sem terem feito concurso publico. Isto porque, aceitar-se tal argumento, sem uma análise de mérito, redundaria em eventualmente beneficiar-se o infrator, porquanto tais entidades públicas poderiam passar a contratar pessoas necessárias a sua atividade-fim, sob as mais diversas modalidades, inclusive fraudulentas e, posteriormente, simplesmente alegarem a inocorrência do concurso público para furtar-se à responsabilidade pelos direitos trabalhistas de tais pessoas, situação que evidentemente não pode ser acobertada pelo Judiciário. " 9
\end{abstract}

Configurada a impossibilidade de efetivação do vínculo empregatício do obreiro, deve ser-lhe facultado ao menos a equiparação salarial com os concursados. Atitude em contrário configuraria discriminação do trabalho realizado e enriquecimento ilícito por parte do tomador. Tal indenização não exclui os danos decorrentes do ato ilícito praticado pelo tomador, fulcro nos arts. 186 e 927 da Código Civil, se existentes.

O Tribunal Superior do Trabalho já firmou posicionamento em favor da equiparação salarial de empregado terceirizado de empresa pública que exercia atividade fim da empresa:

RECURSO DE REVISTA. TERCEIRIZAÇÃO. EMPREGADA DA EMPRESA PRESTADORA DE SERVIÇOS E DA TOMADORA. ISONOMIA SALARIAL. A Corte Regional manteve a decisão em que se reconheceu o direito da Autora às mesmas vantagens dos empregados da segunda Reclamada (CEF), porquanto desempenhava atividades típicas de um bancário, ligadas às atividades-fim da tomadora de serviços. Decisão regional em conformidade com a Orientação Jurisprudencial $n^{\circ} 383$ da SBDI-I desta Corte. Violação dos arts. $7^{\circ}$, XXXII, e 37, II da CF/88 e 461 e 611 da CLT e contrariedade à Súmula $n^{o} 363$ desta Corte Superior não demonstradas. Por fim, estando a decisão recorrida em conformidade com a jurisprudência desta Corte Superior, o conhecimento do recurso de revista por divergência jurisprudencial encontra óbice na Súmula no 333 desta Corte e no

\footnotetext{
${ }^{9}$ AR. Proc. $n^{o}: 00972 / 1998-9 ;$ TRT $2^{a}$ Região; Relatora Juíza VANIA PARANHOS.
} 
$\S 4^{o}$ do art. 896 da CLT. Recurso de revista de que não se conhece. ${ }^{10}$

\section{DA INCONSTITUCIONALIDADE DA MP 520}

Relevância e Urgência são os dois pressupostos para a edição de uma Medida Provisória. A jurisprudência do nosso Supremo Tribunal Federal evidencia que há relevância e urgência sempre que há situação de fato que motiva a edição de medida provisória explicite estado de necessidade a exigir do Governo ação cautelar ante o perigo de demora na edição de ato normativo.

Ainda que se pudesse argumentar, em tese, que a grave situação em que se encontra a saúde pública no Brasil pudesse justificar a adoção de medidas extremas, é preciso considerar que a situação hoje existente na saúde do país não é nova e é, em grande medida, resultado da omissão do próprio Governo Federal.

Com fulcro em todas estas questões que ensejariam a inconstitucionalidade da MP 520, foi ajuizada pelo Partido Social da Democracia Brasileira a Ação Direta de Inconstitucionalidade (ADI 4605), no Supremo Tribunal Federal (STF) contra este ato normativo que criaria a Empresa Brasileira de Serviços Hospitalares (EBSERH) para apoiar a prestação de serviços médico-hospitares, laboratoriais e de ensino e pesquisa nos hospitais universitários federais.

Para o partido, a MP violaria as regras constitucionais da autonomia universitária e do concurso público, além de constar da falta dos requisitos essenciais e necessários de relevância e urgência que caracterizam o ato normativo.

A agremiação afirma que o objetivo da medida é claro: permitir que a contratação de pessoal para os hospitais universitários escape à obrigatoriedade do concurso público.

\section{COMPARATIVO COM MODELOS DE GESTÃo SIMILARES JÁ IMPLANTADOS}

Nosso estado abriga dois modelos de gestão similares ao que se cogitou implantar. O Hospital de clínicas de Porto Alegre, ligado a UFRGS, funciona como uma empresa pública, ligada ao MEC. Tem seu atendimento voltado exclusivamente ao SUS.

\footnotetext{
${ }^{10}$ Proc. RR - 86500-53.2006.5.03.0001; Data de Julgamento: 01/06/2011; Relator Ministro: Fernando Eizo Ono, $4^{\text {a }}$ Turma.
} 
Já o Grupo Hospitalar Conceição (GHC), formado por quatro hospitais, 12 postos de saúde e três centros de atenção Psicossocial, tem estrutura de sociedade de economia mista vinculada ao Ministério da Saúde. O GHC não atende planos de saúde, sendo também exclusivo ao SUS.

São instituições dotadas de autonomia administrativa e orçamentária, gestão profissionalizada e mecanismos de governança, sendo reconhecidas pela eficácia de seus serviços.

Cabe ressaltar pesquisa realizada em 2006, visando medir a eficiência de 31 hospitais Universitários em todo o país, em que o HCPA foi considerado o mais eficiente. $\mathrm{Na}$ pesquisa foram analisadas relações entre, por exemplo, número de internações/leito, de cirurgias por sala, de residentes e mestrandos e doutorandos com os recursos humanos (médicos, funcionário, docentes) e financeiros disponíveis. O GHC não consta nessa pesquisa por não se tratar de Hospital Universitário, mas sim de grupo de instituições de saúde. ${ }^{11}$

\section{CONSIDERAÇÕES FINAIS}

A edição da MP 520, no último dia do governo Lula, reveste-se de uma faceta ditatorial. Tal medida visava a inibir a participação popular, resolvendo no último momento um problema que está em pauta desde 2006. A não votação somente postergou o debate, não tomando nenhuma medida a fim de solucionar a questão.

A atual situação dos Hospitais Universitários é insustentável. Concordamos com o entendimento do TCU, da necessidade de escolher um caminho, seja a ampliação de concursos públicos ou a instituição de outra forma de contratação legal.

Não é nosso objetivo, todavia fazer um juízo de valor quanto a qual o melhor mecanismo a ser implantado. Deve ser realizado um debate na sociedade sobre a melhor forma de gestão desse patrimônio público tão sensível e necessário. Essa discussão tem parte no processo legislativo ordinário, espaço destinado aos representantes fazerem prevalecer a vontade popular.

\section{REFERÊNCIAS BIBLIOGRÁFICAS}

\footnotetext{
${ }^{11}$ LINS, Marcos Estellita et al . O uso da Análise Envoltória de Dados (DEA) para avaliação de hospitais universitários brasileiros. Ciênc. saúde coletiva, Rio de Janeiro, v. 12, n. 4, ago. 2007.
} 
ADIN 4605 - Petição inicial. Disponível em: <http://www.stf.jus.br/>. Acesso em: 15 jun. 2011.

BONOTO, Carolina; CASTILHO, Marina Martinuzzi; DORNELLES, Vitor Tassinari. O Futuro dos Hospitais Universitários. Revista .txt. Edição 13, ano 4, maio 2011. Disponível em <http://issuu.com/revistatxt/docs/revista_txt_ed13/>. Acesso em 27 de jun. de 2011.

BRASIL. Constituição da República Federativa do Brasil de 1988. Disponível em: <http://www.planalto.gov.br/ccivil_03/constituicao/constitui\%C3\%A7ao.htm/>. Acesso 28 de mai. 2011.

BRASIL. Lei $\mathrm{n}^{\mathrm{o}} 8.858$ de 20 de dezembro de 1994. Disponível em: <http://www.planalto.gov.br/ccivil_03/Leis/L8958.htm/>. Acesso em 28 de mai. 2011.

BRASIL. Lei $\mathrm{n}^{\mathrm{o}} 10.973$ de 2 de dezembro de 2004. Disponível em: <http://www.planalto.gov.br/ccivil_03/_ato2004-2006/2004/Lei/L10.973.htm>. Acesso em 28 de mai. 2011.

BRASIL. Medida provisória $\mathrm{n}^{\mathrm{o}} 520$ de 31 de dezembro de 2010. Disponível em: <http://www010.dataprev.gov.br/sislex/paginas/45/2010/520.htm>. Acesso em 14 de jun. de 2011.

FASUBRA. Análise preliminar da MP 520. Disponível em: <http://www.fasubra.org.br/phocadownload/documentos/hu/ANALISE_MP_520_DN_2 0_JAN_2011.pdf>. Acesso em 28 de mai. de 2011.

LINS, Marcos Estellita et al . O uso da Análise Envoltória de Dados (DEA) para avaliação de hospitais universitários brasileiros. Ciênc. saúde coletiva, Rio de Janeiro, v. 12,4 n. 4 , ago. $2007 . \quad$ Disponível em <http://www.scielo.br/scielo.php?script=sci_arttext\&pid=S141381232007000400020\&lng=pt\&nrm=iso>. Acesso em 20 jun. 2011. 
VIANA, Aline. MP 520/10 muda regras da contratação de servidores. Disponível em $<$ http://jcconcursos.uol.com.br/Concursos/Concursos-Previstos/MP-52010-mudaregras-da-contratacao-32700>. Acesso em 12 de mai. de 2011.

TRIBUNAL SUPERIOR DO TRABALHO. Súmulas. Disponível em <http://www.tst.gov.br/jurisprudencia/Livro_Jurisprud/livro_pdf_atual.pdf >. Acesso em 14 de jun. de 2011. 